Original Article

\title{
Traumatic Tympanic Membrane Perforation in Lokoja, Nigeria: A Review of 43 Cases
}

\section{Stephen Agbomhekhe Ogah}

Consultant Otolaryngologist, Head and Neck Surgeon. Department of Surgery, Federal M edical Centre Lokoja, Kogi State, P.O.Box 1256, Nigeria.

*Corresponding Author : Stephen Agbomhekhe Ogah, Consultant Otolaryngologist, Head and Neck Surgeon.Department of Surgery, Federal M edical Centre Lokoja, Kogi State, P.O.Box 1256, Nigeria. Mobile: +2348075224222, E-mail : stephenogah@yahoo.com.

Received

:03.08.2016

Review Completed : 28.10.2016

Accepted

$: 02.11 .2016$

Keywords : Traumatic, tympanic membrane, perforation, review, cases

\begin{tabular}{|c|}
\hline Access this article online \\
\hline Quick Response Code \\
\hline
\end{tabular}

\section{Abstract}

Background : The tympanic membrane main function is the conduction of sound waves for effective hearing hence its perforation almost always results in initial hearing impairment of a reasonable degree.

Objectives : To identify common causes, clinical presentation and management outcome of a perforated tympanic membrane.

Methods : This is a three year (January 2013-December 2015) prospective hospital base study carried out in the ENT Outpatient clinic of the Federal M edical Centre, Lokoja, Nigeria. Patients were recruited by convenience sampling method after a clinical diagnosis of traumatic tympanic membrane perforation. All patients were made to have PTA for their hearing assessment during and after treatment.

Results: A total of 49 patients were recruited but 6 were lost to follow up, the remaining 43 were 24 males and 19 females with a male to female ratio of 1.26:1. Age range was from 2-80years and the modal age group was 11-20years. Ear cleaning and scratching with pointed objects was the commonest cause of traumatic tympanic membrane perforation followed by slapping from assault. Pain was the most common symptom at presentation followed by hearing loss. Spontaneous healing of the membrane occurred in 6 weeks in $34.9 \%$ of the patients and with complete restoration of hearingin $96 \%$.

Keywords: traumatic, tympanic membrane, perforation, review, cases.

\section{Introduction}

The tympanic membrane (TM) forms majorly the lateral wall of the middle ear cleft and the medial end of the external auditory canal were it makes an angle of about 55 degrees with the canal floor. It is oval in shape and measures approximately $10 \mathrm{~mm}$ in vertical diameter and $5 \mathrm{~mm}$ in horizontal diameter. It has three layers, the inner mucosal layer, the middle fibrous layer and the outer epidermal layer which continued with the skin of the auditory canal. The TM is divided into an upper smaller pars flaccida and a larger lower pars tensa. The pars flaccida is the triangular area above the malleolar folds, devoid of the middle fibrous layer and is less prone to injury from the exterior. The pars tensa is larger, below the maleollar folds and more prone to injury from the exterior end. Blood supply is from the branches of the maxillary and the posterior auricular arteries. While the nerve supply is from the $5^{\text {th }}(\mathrm{Vc}), 9^{\text {th }}$ and the $10^{\text {th }}$ cranial nerves [1].

The tympanic membrane main functions are to amplify, transmit and proper routing of sound waves for effective hearing, hence its perforation almost always results in initial hearing impairment of a reasonable degree. Due to the rich blood and abundant nerve supply, pain with blood in the external auditory canal is a common presentation [2]. Causes of tympanic membrane perforation may include, cleaning the ears with cotton wool applicator, scratching the ear with objects like match stick or pencil or biro cover, ear syringing, foreign body removal from the ear, road traffic injury involving the ear or the petromastoid region, slapping, vigorous kissing of the ear by lovers, blast 
from missiles, barotraumas have all been reported [3]. Tympanic membrane perforation is said to have been under reported in literature in most part of the world [4]. With this low awareness, the problem cannot be given the necessary enlightenment campaign for its prevention.

Perforation symptoms may include pain, decrease in hearing, bloody otorrhea, tinnitus, vertigo, fullness in the ear, audible whistling of sound during sneezing or when blowing the nose, and purulent drainage when infected especially when the canal is not kept dry [5]. The hearing loss is said to have a linear relationship with the size of the perforation [6].

Diagnosis is usually based on the clinical history, otomicroscopy and impedance studies of the tympanic membrane. Turning fork test and PTA can be done to detect the conductive hearing loss. Valsalva maneuver with the ear canal filled with sufficient distilled water or sterile saline to cover the TM can produce air bubbles only if the TM isperforated [7].

\section{Materials and Methods}

This is a three year (January 2013-December 2015) prospective hospital base study carried out in the ENT Outpatient clinic of the Federal Medical Centre, Lokoja, Nigeria. Patients were recruited by convenience sampling method after a clinical diagnosis of traumatic tympanic membrane perforation from history and clinical examination using Hysne's otoscope. All patients were made to have PTAs for their hearing assessment during and after treatment except those with severe head injury. They were treated conservatively with prophylactic antibiotics, analgesics, and with an instruction for patients to keep their ears dry. Patients were followed up until their perforations werehealed or lost to follow up.

\section{Results}

A total of 49 patients were recruited during the study period but 6 of them were lost to follow up, the remaining 43 were 24 males and 19 females with a male to female ratio of 1.26:1. Age range was from 2-80years and the modal age group was 11-20years (table-1). Ear cleaning and scratching with pointed objects was the commonest cause of traumatic tympanic membrane perforation followed by slapping from assault (table-2). Pain was the most common symptom at presentation followed by hearing loss (table-3). Spontaneous healing of the membrane occurred in 6 weeks in $34.9 \%$ of the patients and with complete restoration of hearing in $96 \%$ (tables4and5).

Table 1 : Age distribution

\begin{tabular}{|l|l|}
\hline Age Group & Number of Patients (\%) \\
\hline $0-10$ & $09(20.9)$ \\
\hline $11-20$ & $11(25.6)$ \\
\hline $21-30$ & $06(14.0)$ \\
\hline $31-40$ & $07(16.3)$ \\
\hline $41-50$ & $02(4.6)$ \\
\hline $51-60$ & $03(7.0)$ \\
\hline $61-70$ & $04(9.3)$ \\
\hline $71-80$ & $01(2.3)$ \\
\hline Total & $43(100.0)$ \\
\hline
\end{tabular}

Table 2 : Causes of TM Perforation

\begin{tabular}{|l|c|}
\hline Trauma type & $\begin{array}{c}\text { Number of } \\
\text { Patients (\%) }\end{array}$ \\
\hline Ear cleaning/Scratching & $15(34.9)$ \\
\hline Slap from people/Assault & $12(28.0)$ \\
\hline Road Traffic Injury & $08(18.6)$ \\
\hline Foreign body Removal by Quacks & $05(11.6)$ \\
\hline Blast & $01(2.3)$ \\
\hline Fall from Height & $01(2.3)$ \\
\hline Children putting objects into other ears & $01(2.3)$ \\
\hline Total & $43(100.0)$ \\
\hline
\end{tabular}

Table 3 : Clinical Presentation

\begin{tabular}{|l|c|}
\hline $\begin{array}{l}\text { Presenting Signs and Symptoms } \\
\text { Pain }\end{array}$ & $\begin{array}{c}\text { Number of Patients (\%) } \\
41(95.3)\end{array}$ \\
\hline Hearing loss & $38(88.4)$ \\
\hline Bloody Discharge & $32(74.4)$ \\
\hline Tinnitus & $5(11.6)$ \\
\hline Purulent Discharge & $3(07.0)$ \\
\hline vertigo & $2(4.7)$ \\
\hline Headaches & $1(2.3)$ \\
\hline
\end{tabular}

Table 4 : Time for Perforation to heal

\begin{tabular}{|l|c|}
\hline Time for the Uninfected Ear to Heal & Number of Patients (\%) \\
\hline 1 Week & $0(00.0)$ \\
\hline 2 Weeks & $0(00.0)$ \\
\hline 3 Weeks & $2(4.7)$ \\
\hline 4 Weeks & $3(7.0)$ \\
\hline 5 Weeks & $7(16.3)$ \\
\hline 6 Weeks & $15(34.9)$ \\
\hline 7 Weeks & $5(11.6)$ \\
\hline
\end{tabular}




\begin{tabular}{|l|c|}
\hline Time for the Uninfected Ear to Heal & Number of Patients (\%) \\
\hline 8 Weeks & $4(9.3)$ \\
\hline 9 Weeks & $3(7.0)$ \\
\hline 10 Weeks & $2(4.6)$ \\
\hline 11 Weeks & $1(2.3)$ \\
\hline 12 Weeks & $1(2.3)$ \\
\hline Total & $43(100.0)$ \\
\hline
\end{tabular}

Table 5 : Outcome

\begin{tabular}{|l|c|}
\hline Spontaneous Healing & Number of Patients (\%) \\
\hline Without Residual hearing Loss & $37(86 \%)$ \\
\hline With Residual hearing Loss & $6(14 \%)$ \\
\hline
\end{tabular}

\section{Discussion}

In this study the modal age group is 11-20years and this is not surprising as many of our patients with tympanic membrane perforation are children and adolescent still under the care of their parents. Our women see it as a duty to daily clean their children's ears despite it is not right and this may be responsible for the high incidence in this age group. The inherent danger in the used of cotton wool applicator for cleaning the external auditory canal has been long been reported in literature [8]. As in

\section{References}

1 Michael Gleeson: Scott-Browns, Otolaryngology \& Head-Neck Surgery; $7^{\text {th }}$ edition; Hodder Arnold 2008; 3: 3261-3275.

2. Da Lilly-Tariah $\mathrm{OB}$ and Somefun AO: Traumatic perforation of the tympanic membrane in University of Port Harcourt Teaching Hospital, Port Harcourt. Nigeria., Niger Postgrad M ed J 2007.

3. Golam Rabbani SM, Rashid A, Mahmud K, Chowdhury M A and Razzak A. Traumatic Rupture of Tympanic Membrane: A Study of 70 Cases. Bangladesh J Otorhinolaryngol 2015; 21(1): 38-42

4. Sarojamma, Saurabh Raj, H.S Satish. A Clinical Study of Traumatic Perforation of Tympanic Membrane. IOSR Journal of Dental and Medical Sciences. 2014; 13(4): 24-28.

5. Orji FT and Agu CC. Determinants of spontaneous healing in traumatic perforations of the tympanic membrane. Clin Otolaryngol. 2008 Oct;33(5):420-6

[6] Lerut B, Pfammatter A, M oons ], Linder T. Functional correlations of tympanic membrane perforation size. Otol Neurotol. 2012 Apr. all other traumatized tissues in the body so also in the ear that pain is the most common presenting symptom in patients with trauma as found in this study. However, if the perforation had occurred weeks earlier and patient had started treatment it may not be that obvious. Hearing loss is the second most common symptom found in this study and is in agreement with what had been reported by other researchers. It has been found to be directly proportional to the size of the perforation [9]. In this study, 35\% had spontaneous healing of their membrane at 6 weeks with conservative treatment. However, healing may be delayed by infection, not keeping the canal dry, malnutrition, thermal injury, co-morbidity, very large perforation etc. In such a case some researchers found EGR and the use of ciprofloxacin ear drop to be useful in healing of medium size perforations [10, 11]

\section{Conclusion}

Traumatic tympanic membrane perforation can be avoided by educating people about the danger of ear cleaning especially with the cotton tip applicator and the prognosis is good if patient is referred early to the ENTSurgeon for appropriate treatment.

\section{3(3):379-86}

7. Park H, Hong SN, Kim HS, et al. Determinants of conductive hearing loss in tympanic membrane perforation. Clin Exp Otorhinolaryngol. 2015Jun. 8 (2):92-6

8. Wohlgelernter J, Gross M, Eliashar R. Traumatic perforation of tympanic membrane by cotton tipped applicator. J Trauma 2007; 62:1061

9. Hempel JM 1, Becker A, Müller J, Krause E, Berghaus A, Braun T. Traumatic tympanic membrane perforations: clinical and audiometric findings in 198 patients. Otol Neurotol. 2012 Oct; 33(8):1357-62.

10. Jian-Yang, Zi-Han-Lou, Yahui-Fu, Zheng-Cai-Lou. A retrospective study of EGF and ofloxacin drops in the healing of human large traumatic eardrum perforation. Am J Otolaryngol. $2016 \mathrm{M}$ ar 22.

11. Lou Z, Lou Z, Tang Y, Xiao J. The effect of ofloxacin otic drops on the regeneration of human traumatic tympanic membrane perforations. Clin Otolaryngol. 2015 Oct 14 